\title{
موقف القضاء من ركن الاختصاص في القرار الإداري
}

فهد سلامه ضيف الله القضاه

المملكة الأردنية الهاشمية

Fahed.algudah@yahoo.com

قبول البحث: 2020/12/23 
www.refaad.com
المجلة الدولية للدراسات القانونية والفقهية المقارنة

International Journal of Legal and Comparative Jurisprudence Studies (LCJS)

Journal Homepage: https://www.refaad.com/views/LCJS/Home.aspx

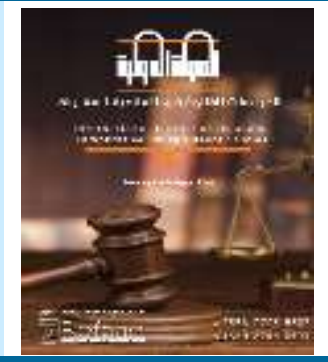

ISSN: 2708-6607(Online) 2708-6593(Print)

\title{
موقف القضياء من ركن الاختصـاص في القرار الإداري
}

\author{
فهد سلامه ضيف الله القضياه \\ المملكة الأردنية الهاشمية
}

Fahed.algudah@yahoo.com

DOI: https://doi.org/10.31559/LCJS2021.2.1.6 2020/10/8 مراجعة البحث: 2020/11/5 قبول البحث: 2020/12/23

الملخح:

يعرف ركن الاختصاص في القرار الإداري على أنه: القدرة القانونية على مباشرة عمل إداري معين، فالقرار الإداري يجب ني يصدر عن

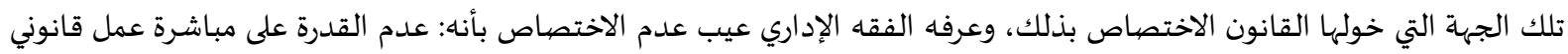

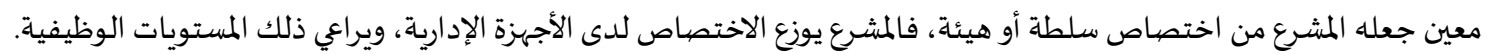

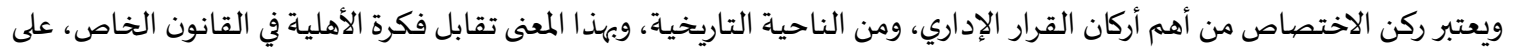

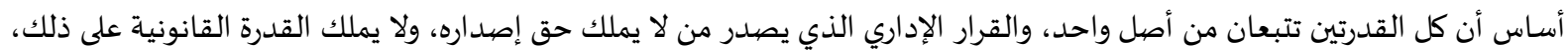
يكون مصيره البطلان.

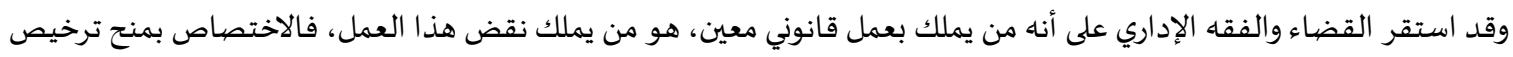
معين يقتضي ضمنا الاختصاص، بسحب هذا الترخيص إلا أن هذه القاعدة غير مطلقة.

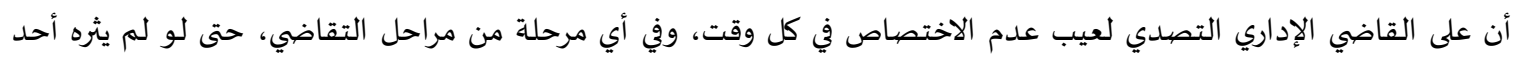
الخصوم، وذلك كسبب من أسباب الغاء القرار الإداري، وذلك كون ركن الاختصاص مرتبط الإن بالن النظام العام. الكلمات المفتاحية: قرار إداري؛ قضاء؛ اختصاص.

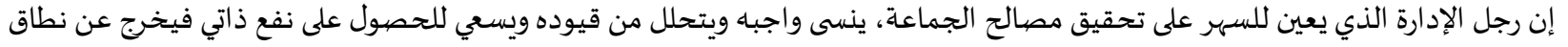

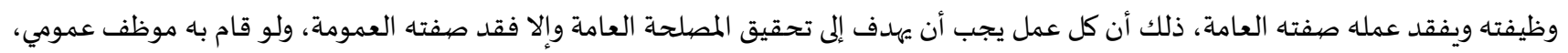

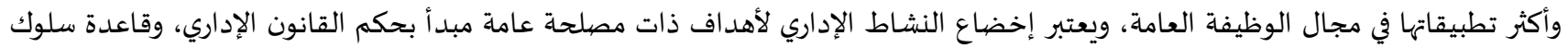
إجبارية، ويلتزم بها كافة موظفي الدولة في ممارستهم لنشاطهم لإداري.

مشكلة الدراسة:

تتمثل مشكلة هذه الدراسة على التعرف على ركن الاختصاص في القرار الإداري، وتسعى هذه الدراسة إلى الإجابة على هذه الأسئلة التالية:

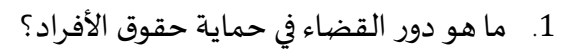

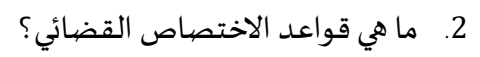

3. ما هو موقف رجل الإدارة من القرار الإداري؟ ماعد الإئ 
4. ما هي مصادر ركن الاختصاص؟

5. ما هي عناصر ركن الاختصاص؟ مي من الاختصاص؟

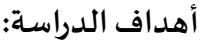

تسعى هذه الدراسة إلى تحقيق الأهد اف التالية:

1. التعرف على ركن الاختصاص في القرار الإداري.

2. التعرف على مصيادر ركن الاختصياص

3. التعرف على عناصر ركن الاختصياص

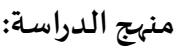

المنهج المقارن: يعتمد هذا المنهج على موقف التشريع الأردني، وموقف التشريعات العربية من هذا الإجراء.

\section{المبحث الأول: مصادر ركن الاختصاص في القرار الإداري}

إن المشرع هو من يتولى توزيع الاختصاصات، وتعيين الجهات التي تملك صلاحية التعبير عن الإرادة، وتحديد الأشخاص المخاطبين بالقرار

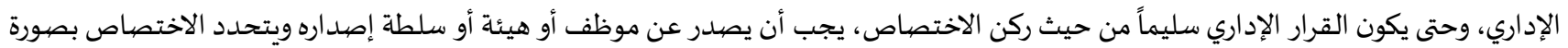

مباشرة أو غير مباشرة. أما الصورة المباشرة والمتمثلة في التشريع (الدستور، القوانين، الأنظمة) ومن الأمثلة عليها مبدأ توازي الاختصاص، والاشكال، والإجراءات الذي يفضي بأن من يملك إصدار القرار هو وحده من يملك إلغاءه.

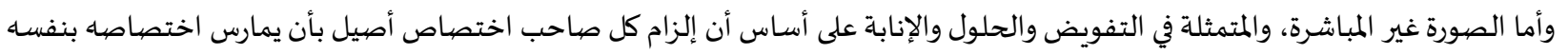

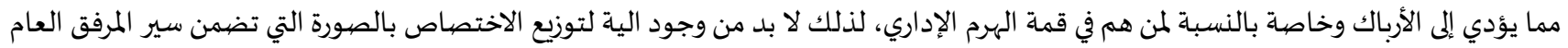
بانتظام وإطراد. المطلب الأول: التشريع إنه من الأصل أن يقوم المشرع بتوزيع الاختصاص بين مختلف مستويات التنظيم الإداري وعليها أن تلتزم بهذا الحـدود، ولكن قد يستمد رجل الإدارة

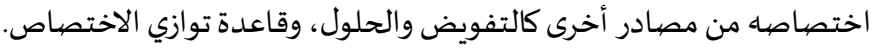

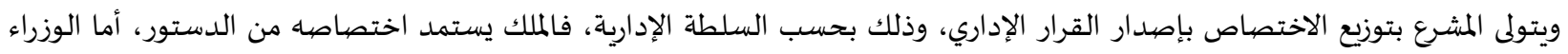

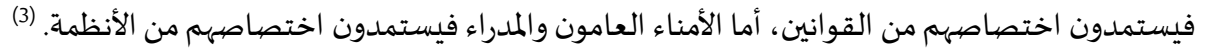

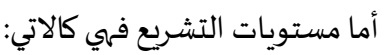

أولاً: القاعدة الدستورية:

يحدد الدستور عادة الاختصاصات لكل سلطة من سلطات الدولة الثلاثة، وذلك من مبدأ الفصل ما بين السلطات، فالدستور الأردني حدد

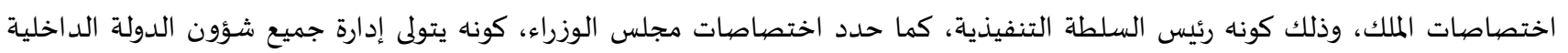

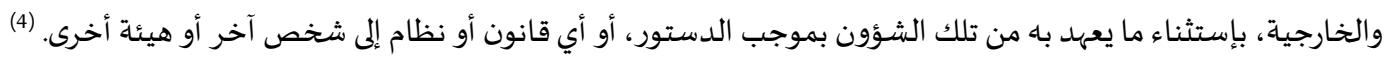
ثانياً: القو انين والأنظمة: تعتبر القوانين والأنظمة هي من أهم مصادر قواعد الاختصاص، واوسعها تطبيقاً، وذلك لأن الصلاحيات التي يتمتع بها أعضياء السلطة الإدارية

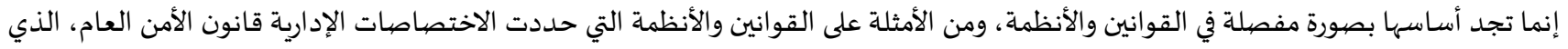

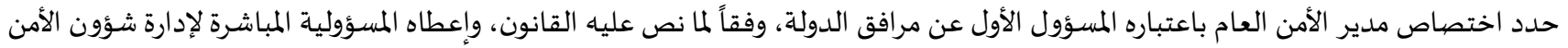

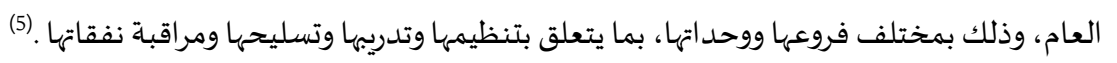

1 الدكتور عبد الغني بسيوني عبد الله، التنظيم الإداري، منشاة دار المعارف بالإسكندرية، 2004، ص 116 2 3 الدكتور عبد الغني بسيوني عبد الله، التنظيم الإداري، منشاة دار المعارف بالإسكندرية، 2004، ص 116

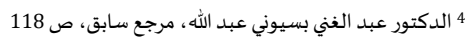

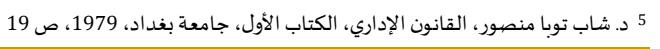


أما على صعيد الأنظمة والتي يقصد بها " مجموعاة القواعد القانونية المكتوبة الصادرة عن السلطة التنفيذية أثناء ممارستها الوظيفة العامة."

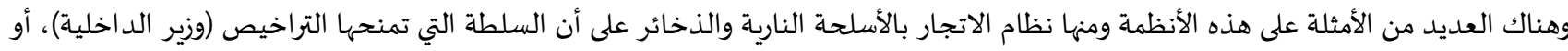

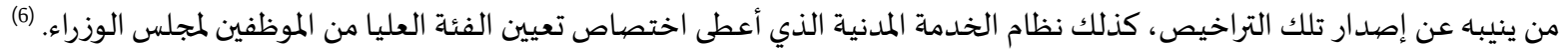

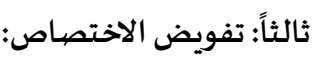
ويقصد بتفويض الاختصاص: هو أن يعهد صاحب الاختصاص الأصيل بجزء من اختصاصيا إلى بعض مرؤوسيه وفقاً لأحكام القانون وبهذا المعني

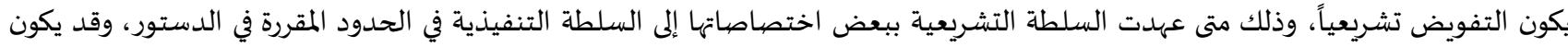

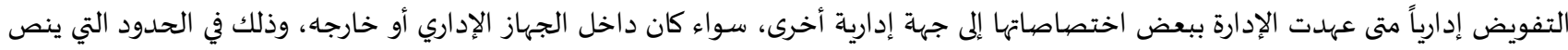
علها القانون. (7) إن التفويض في الاختصاص من شأنه أن يخلق صف ثاني من القيادات المدربة، ورفع المعنوية للموظف، الذي يفوض إليه الاختصاص، وشعوره بالقدرة على تحمل المسؤوليات إلا أن تفويض الاختصاص يعد خروجاً وإستثناء على هذه القاعدة، ولا يجوز اللجوء إليها إلا ضمن شروط منها: 1 لا يجوز تفويض الاختصاص من الموظف الأصيل إلى موظف آخر إلا بوجود نص قانوني يجيز التفويض، كذلك لا يجوز للموظف الأصيل التنازل

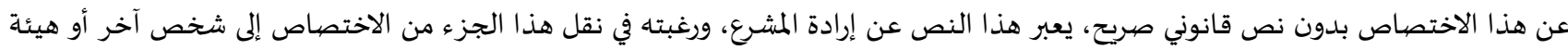

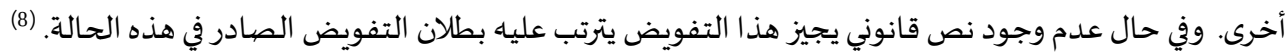
2. أن يصيدرقرار التفويض من الأصيل يجب أن يكون التفويض بقرار يصدر من الأصيل إلى المفوض إليه ويسمى (قرار التفويض)، وهنا يجب أن يلتزم الأصيل بحدود النص القانون

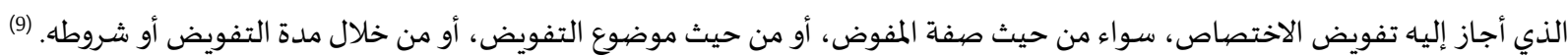
3. أن لا يكون التفويض في كافة الاختصاصات وإلا كان ذلك عبارة عن تنازل عن السلطة، وهذا يتنافى مع الحكمة من التفويض، إلا أن هناك من

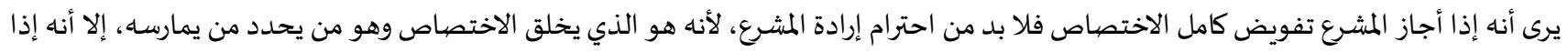

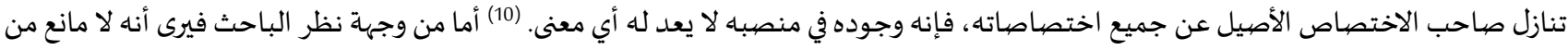

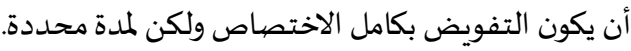

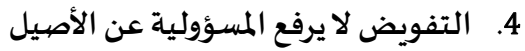

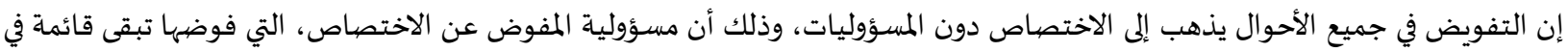

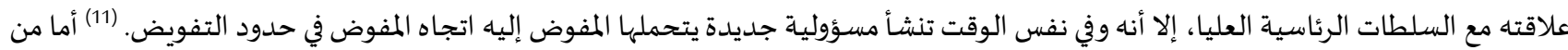
وجهة نظر الباحث فيرى أن تكون كامل المسؤولية على المفوض إليه.

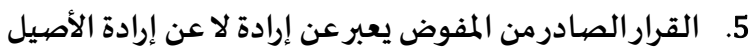

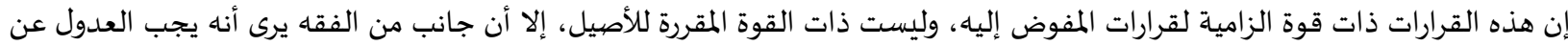

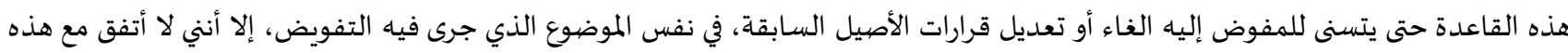
النظرية لأن الأصيل يفترض وجوده وعدم غيابه، ويمكن الرجوع إليه لإجراء التعديل والإلغاء. (12) أما من وجهاء نظر الباحث فإنه يرى أنه يجب إعطاء المفوض إليه كامل الصلاحيات في تعديل وإلغاء لقرارات الأصيل.

6. لا يجوزتفويض التفويض الاض.

الأصل أن لا يقوم المفوض بنقل هذا التفويض بالاختصاص الى غيره مرة أخرى، والهدف من ذلك ضياع المسؤولية، ولكن يستثنى من ذلك إذا اجازالمشرع تفويض التفويض، وذلك بنص صريح.

6 دثروت بدوي، القانون الإداري، دار الهضية العربية، القاهرة، 1974، ص 113

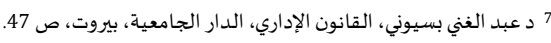
8 د عبد الغني بسيوني، مرجع سابق، ص ص 50

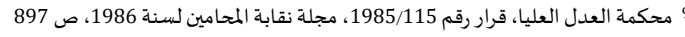

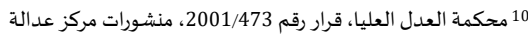

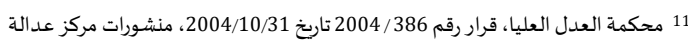
12 محكمة العدل العليا، قرار رقم 5/22، مجلة نقابة المحامين، لسنة 1980، ص ص 1489 


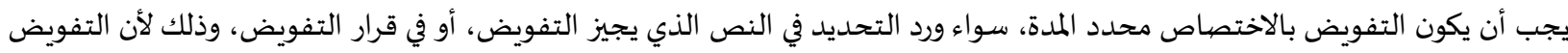

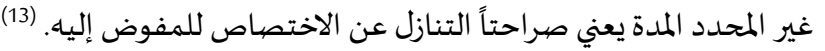

8. يجوزللمفوض ان يمارس الاختصياص

يججوز لمن يفوض بعض اختصاصهاته أن يمار تلك الاختصاصات التي قام بتفويضها المى جانب المفوض إليها، إذا كان هناك مبرر لذلك.

9.

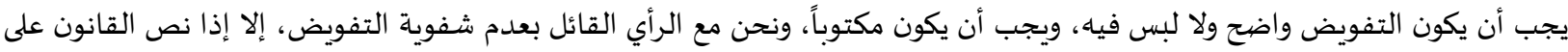
خلاف ذلك، ولكن الفقاه والقضاء الإداري متفقان على وجوب نشر التفويض كي يعلم به الكافة، ويكون حجة على الكافة، حتى لو سكت النص بالتفويض بعدم النشر. (14) المطلب الثاني: الحلول ويقصد بالحلول في الاختصاص: أن يتغيب صاحب الاختصاص الاصيل، أو يحدث مانع يحول دون ممارسته لاختصاصيه، فيحل محله موظف معين في ممارسته للوظيفة ممن عينه المشرع بذلك، وذلك إذا طرأ عيب يمنع صاحب الاختصاص الأصيل من ممارسة اختصاصها. ويمكن تحديد أهم

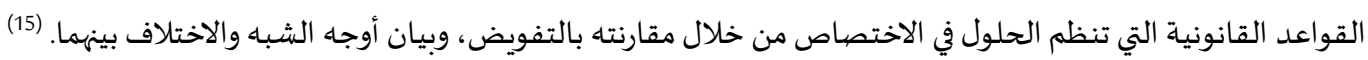
أولاً: يـجب أن يكون هناك نص قانوني يستند إليه:

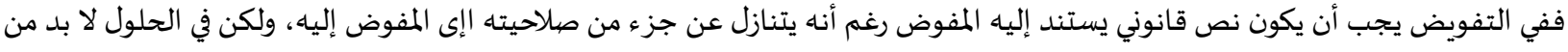
وجود نص قانوني ينشأ إحدى حالات الحلول، ويشترط في النص أن يكون له القوة الإلزامية تعادل قوة النص الذي يعطي الاختصاص لكأل للأصيل أو تعلو

ثانياً: قيام سبب يجعل صاحب الاختصاص الأصيل عاجزعن ممارسة الاختصياص: أن يكون هناك سبب جوهري يمنع صاحب الاختصاص الأصيل يمنع من ممارسته الاختصاص سواء كان ذلك بالنقل أو الاستقالة أو الوقف عن

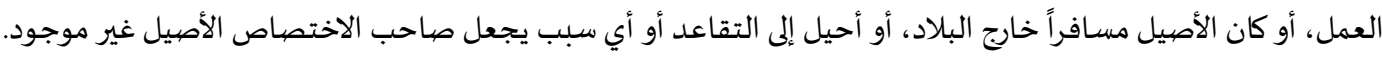
ثالثاً: الحلول في الاختصياص يدوروجودا وعدما مع سببـه: إذا زال سبب الحلول، أي إذا عاد صاحب الاحودوداحتصاص وعلدما الأصيل إلى عمله، كونه كان في إجازة أو مسافر وعاد إلى عمله، وانتهت مدة الاجازة فإن

الحلول ينتهي.

المطلب الثالث: الإنابة أو الوكالة

أحذ المشرع الأردني في نظام ديوان الخدمة المدنية الحالي بالوكالة كمصر من مصادر الاختصاص، ويقصد بالوكالة: صدور قرار بتكليف أحد الموظفين للقيام بمهام وظيفة أخرى شاغرة، وذلك بسبب غياب الأصيل، إضافة إلى مهام وظيفته الأصلية، وهناك العديد من الشروط لصحدة الإنابة

أولاً: وجود مانع يمنع صاحب الاختصاص الأصيل من ممارسته اختصاصها، سواء كان المانع دائم أو مؤقت، وهذا ما أكده نظام ديوان الخدمة المدنية

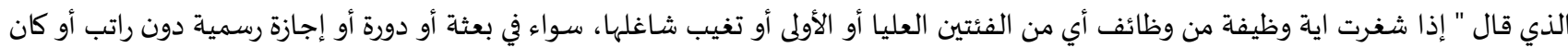
معاراً " (16) ثانياً: وجود نص قانوني يجيز الإنابة سواء وردت في الدستور أو في القانون أو في أية أنظمة، ومثال ذلك أن يصدر رئيس الوزراء أو رئيس الدولة قراراً

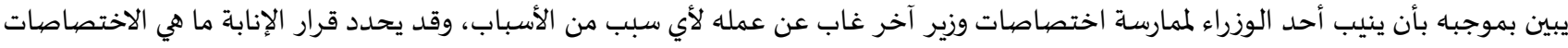

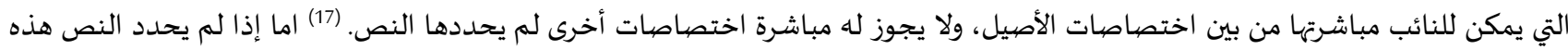
الاختصاصات فإن في ذلك أن يباشر النائب جميع اختصاصيات الأصيل.

13 د عبد الغني بسيوني عبد الله، التنظيم الإداري، منشاءه دار المعارف ، الإسكندرية ، ص 184 الإدار

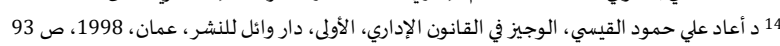

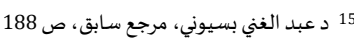

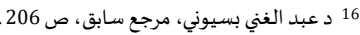

17 د نواف كنعان، القانون الإداري - الكتاب الثاني، دار الثقافة، عمان، 2009 200، ص ص 235. 
ثالثاً: أن يصدر قرار الأنابة من الشخص الذي خوله القانون أو النص التشريعي، والذي بموجبه يحدد النائب، وإلا كان القرار باطلاً، وذلك لعيب عدم

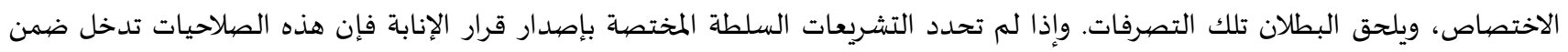

اختصاصات السلطة الرئاسية العليا. (18) رابعاً: أن لا تقل فئة ودرجة الموظف المناب عن فئة ودرجة الموظف الأصيل، أو الفئة أو الدرجة التي تليها، وأن الإدارة ملزمة وهي تختار الموظف المناب

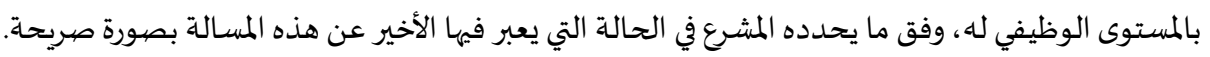

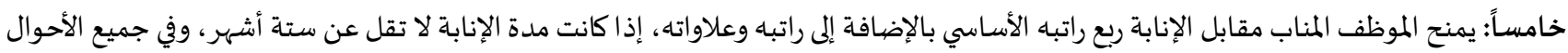

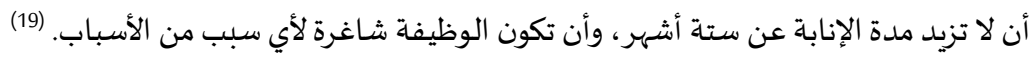

\section{المبحث الثاني: عناصرركن الاختصاص}

هناك مجموعة من العناصر، هي من تحدد فكرة الاختصاص حتى يكون القرار الإداري سليماً ومنتجاً لأثاره القانونية، وهناك عدة عناصر منها

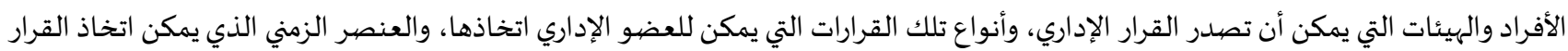

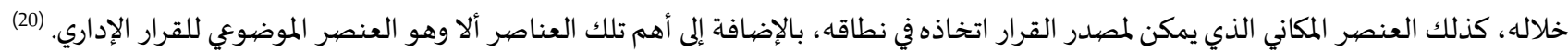

المطلب الأول: الاختصياص الشخصي ويقصد بالعنصر الشخصي في ركن الاختصاص في القرار الإداري، أن يصدر القرار الإداري من الشخص أو الهيئة التي حددها القانون، وفي تلك

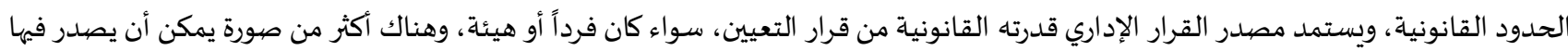

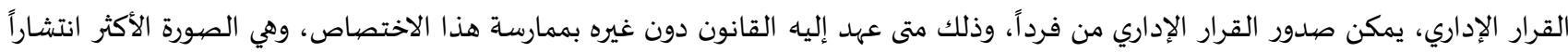

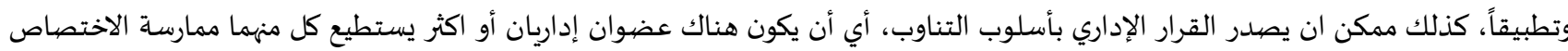

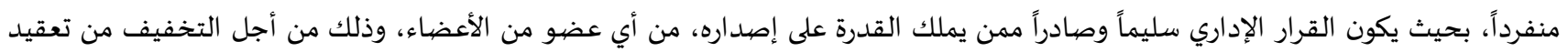

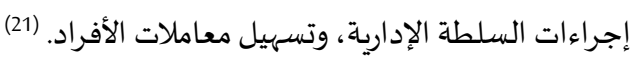
كذلك أن يشترط القانون أن يصدر القرار الإداري من عضوين أو اكثر من أعضياء السلطة الإدارية في وقت واحد، لذادلك لا يستطيع العضيو

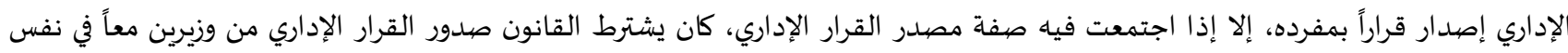

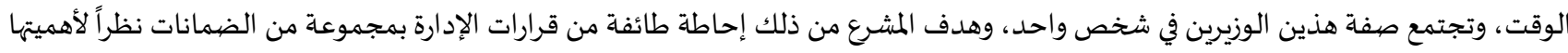

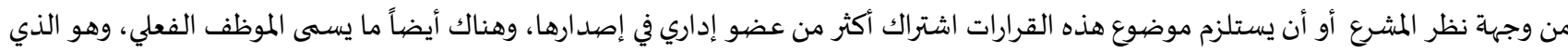

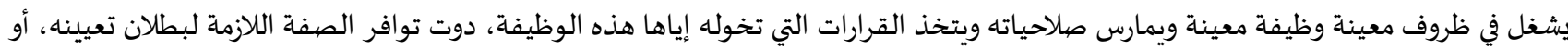
لعدم وجوده من الأصل، وذلك في ظروف معينة تستوجب إضفاء الشرعية على التصرفات الصيادرة منه، واعتبارها كما لو كانت صادرة من موظف عاد عام.

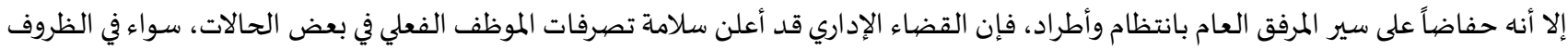

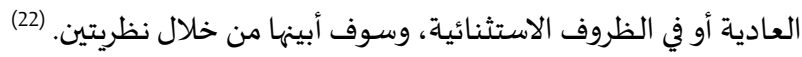

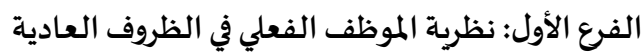

حسب هذه النظرية فإن الموظف الفعلي في الظروف العادية هو الأخذ بالظاهر، وذلك بأن يتعامل الجمهور مع موظف عام يشغل وظيفة عامة، وعليه سوف يتقيد الجمهور بتلك القرارات التي تصدر عنه، وفي نفس الوقت يستفيد من الخدمة التي يحصل عليها، جراء اتخاذ هذه القرارات، لأن

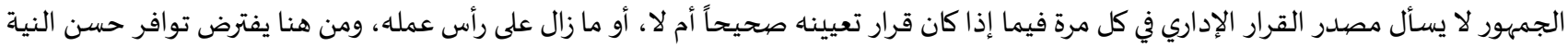
لدى الجمهور، بغض النظر عن توافر حسن النية من مصدر القرار الإداري. (23)

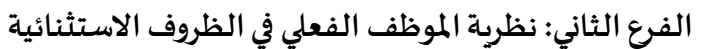
تقوم هذه النظرية على فكرة الضرورة، على الأساس القانوني لنظرية الموظف الفعلي في الظروف الاستثنائية، والتي تتمثل في الظروف الاستثنائية فقط، ولكن هذه النظرية لا تقوم إلا في حالات الحروب الداخلية او الخارجياة، أو في الاضطرابات والكوارث مما يؤدي إلى أن يغادر السكان المناطق التي يقيمون فيها متوجهين إلى إقليم آخر، وتختفي السلطات الشرعية مما يحمل السكان على اختيار مجموعة من بينهم من أجل تصريف أمورهم وإنجاز

18 د سليمان الطماوي، النظرية العامة للقرارات الإدارية، دار الفكر العربي، الطبعة الخامسة، 1984، ص 190

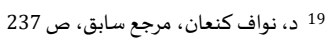
20

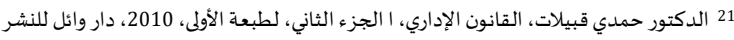

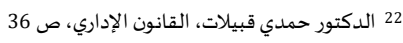

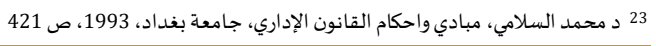


أعمالهم ولضمان سير المرفق العام، وخاصة ما كان منها ضرورياً لحياة الشعب، وحتى لو بقيت الإدارة العليا فإنها هي من تقوم بإختيار مجموعة من

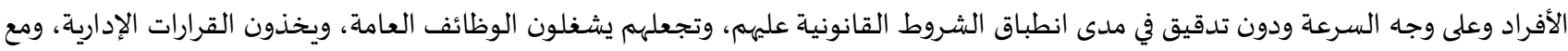

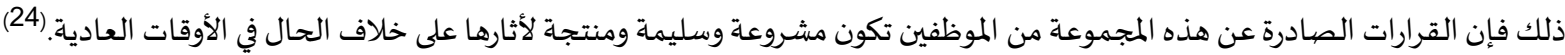

المطلب الثاني: الاختصياص الموضوعي

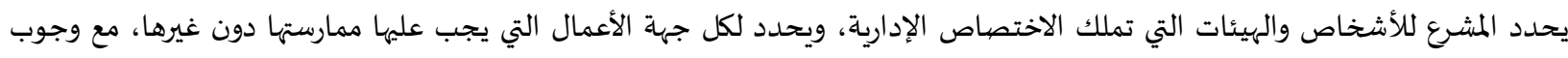

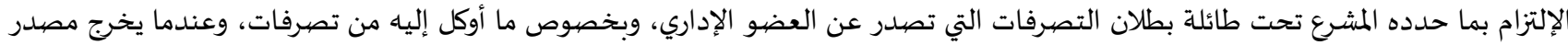
القرار عن القيود الموضوعية للاختصاص، ويخالفها فان ذلك يكون قد اتخذ أحد الصورتين عدم الاختصاص الجسيم، وصورة عدم الاختصياص

البسيط. (25)

الفرع الأول: عدم الاختصاص الجسيم

يكون ذلك عندما يصدر القرار الإداري فاقداً لأحد اركانه الأساسية، فيصبح عبارة عن واقعة مادية، ويترتب عليه البطلان والإنعدام، ولا يولد أي

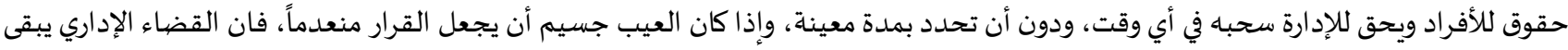

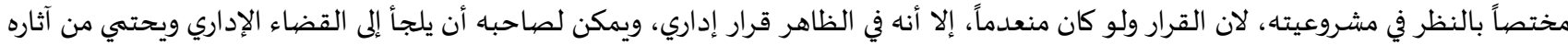

ونتائجة. (26)

ويتفق الفقه والقضاء الإداريان على أن عيب عدم الاختصاص الجسيم إنما يكون في حالتين، الأولى أن يصدر القرار من فرد عادي ليس له صفة

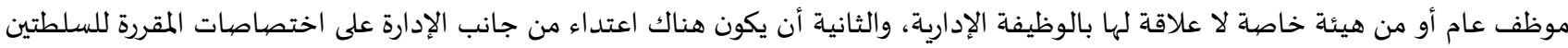

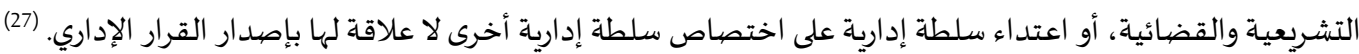

الفرع الثاني: عدم الاختصباص البسيط

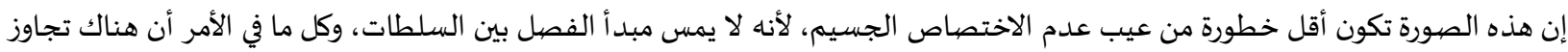

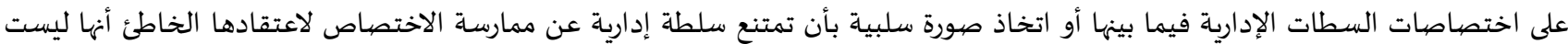

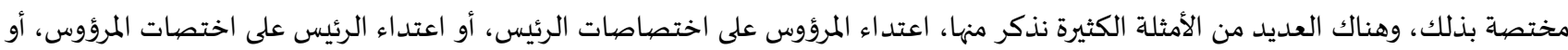
اعتداء هيئة مركزية على اختصاص هيئة غير مركزية والعكس، أو صدور قرار بناء على تفويض أو حلول مخالف للقانون ..الخ (28)

المطلب الثالث: عنصرركن الاختصياص الزمني

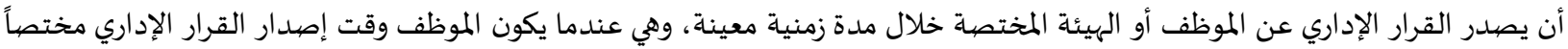

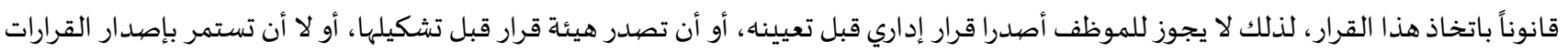

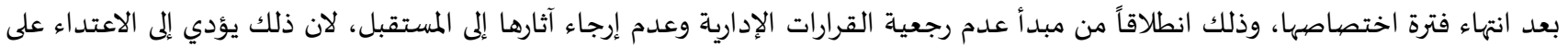
سلطة السلف وسلطة الخلف من ناحية الحلول والانتداب. هناك حالات عدم الاختصاص الزمني في القرارات الإدارية نذكر منها، صدور القرار الإداري عن السلطة الإدارية قبل أن تتولى الوظيفة الإدارية أو

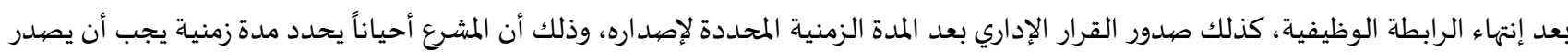
القرار الإداري خلالها.

المطلب الر ابع: عنصر الاختصهاص المكاني

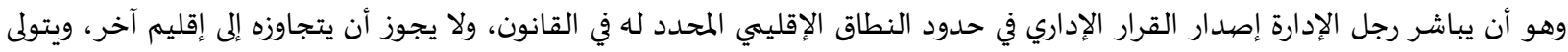

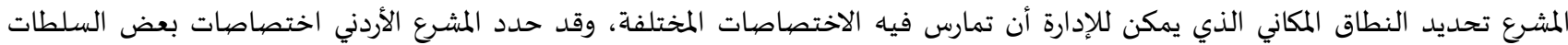

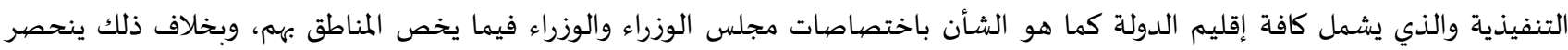
اختصاصهم في نطاق إقليهي محدد، كما هو بالإدارات المركزية والإدارات اللامركزية كالبلديات والمحافظين والمتصرف ومدير القضاء، لذلك يجب على

24 د. حمدي قبيلات، القانون الإداري، ماهية القانون الإداري، التنظيم الإداري، النشاط الإداري، الطبعة الأولى، 2008، دار وائل 25 د. حمدي قبيلات، مرجع سابق، ص 26

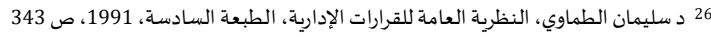

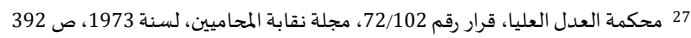

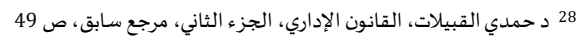


صاحب الاختصاص احترام الحدود المكانية، فإن صدور قرار عن عضو السلطة الإدارية خارج نطاق اختصاصه المكاني، هو قرار معيب يعيب عدم

(29) الاختصياص

ويثور التساؤل أحياناً حول مصير القرارات الإدارية التي يمكن أن تصدر من قبل العضو الإداري وهو بعيد عن مكان عمله، هل هي قرارات

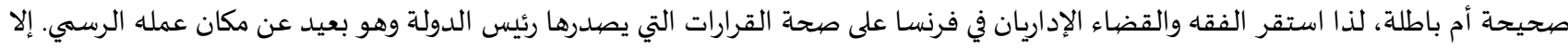

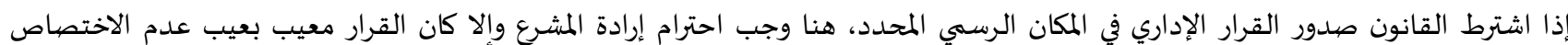

1. بدوي، ثروت (1974). القانون الإد/ري. دار الهضضة العربية. القاهرة، 2. 2. البزرنجي، عصام عبد الوهاب (1971). السلطة التقديرية والرقابة القضيائية ، رسالة دكتوراه. جامعة عين شمس. القاهرة. مصر. 3. خليل، محسن (1982). القضاء الإد/ري اللبناني. دراسة مقارنة. دار النهضية.

4. السلامي، محمد (1993). مبادىء وأحكام القانون الإد/ري. جامعة بغدادئ.

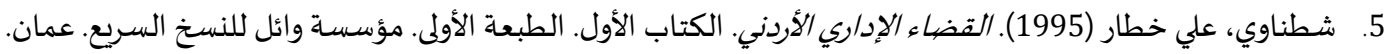

6. الطماوي، سليمان (1966). النظريات العامة في القرارات الإد/رية. الطبعة الأولى. دار الفكر العربي. القاهرة. مصر. 7.

8. عبد الله، عبد الغني بسيوني (د.ت). التنظيم الإداري. منشاءه دار المعارف، الإسكندرية.

9. 10. قبيلات، حمدي (2010). القانون الإد/ري. الجزء الثاني. الطبعة الأولى. دار وائل للنشر.

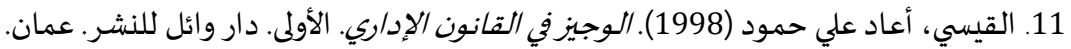

12. كنعان، نواف (2009). القانون الإد/ري - الكتاب الثاني. دار الثقافة. عمان.

13. منصيور، شاب توبا (1979). القانون الإد/ري. الكتاب الأول. جامعة بغداد.

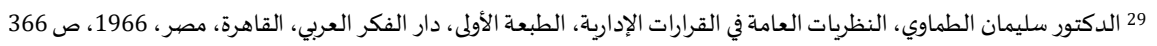

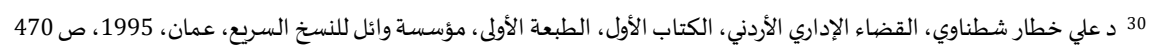




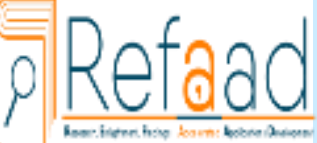

www.refaad.com
المجلة الدولية للدراسات القانونية والفقهيية المقارنة

International Journal of Legal and Comparative Jurisprudence Studies (LCJS)

Journal Homepage: https://www.refaad.com/views/LCJS/Home.aspx

ISSN: 2708-6607(Online) 2708-6593(Print)

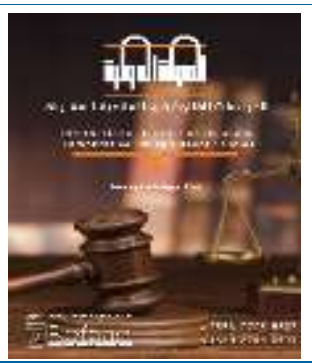

\title{
The position of the judiciary on the corner of jurisdiction in the administrative decision
}

\author{
Fahid Salameh Dheif Allah Alqudah \\ Jordan \\ Fahed.algudah@yahoo.com
}

\author{
Received: 8/10/2020 Revised: 5/11/2020 Accepted: 23/12/2020 DOI: https://doi.org/10.31559/LCJS2021.2.1.6
}

\begin{abstract}
The jurisdiction corner in the administrative decision is defined as the legal ability to carry out a specific administrative work. The administrative decision must be issued by the authority that the law has authorized the jurisdiction to do so, and the administrative jurisprudence defined the defect of lack of jurisdiction as the inability to undertake a specific legal act that the legislator has rendered it the jurisdiction of an authority or body. The legislator allocates competence to the administrative bodies, taking into account the functional levels. (1) Historically, the jurisdiction corner is considered one of the most important administrative decisions, in this sense corresponds to the idea of eligibility in private law.

On the basis that all the two capabilities follow one origin, and the administrative decision issued by someone who does not have the right to issue it and does not have the legal capacity to do so, will be null. (2) The judiciary and administrative jurisprudence have established that who owns a specific legal act is the one who has the power to set aside this act.

The jurisdiction to grant a specific license implies jurisdiction to withdraw this license, but this rule is not absolute. That the administrative judge must address the defect of lack of jurisdiction at all times at any stage of the litigation, even if it is not raised by one of the litigants, this is one of the reasons for canceling the administrative decision, as the jurisdiction pillar is linked to the public order.
\end{abstract}

Keywords: administrative decision; judiciary; jurisdiction.

\section{References:}

1. 'bd Allh, 'bd Alghny Bsywny (D.T). Altnzym Aledary. Mnsha'h Dar Alm'arf, Aleskndryh.

2. Bdwy, Thrwt (1974). Alqanwn Aledary. Dar Alnhdh Al'rbyh. Alqahrh,2.

3. Albzrnjy, 'sam 'bd Alwhab (1971). Alslth Altqdyryh Walrqabh Alqda'yh, Rsalt Dktwrah. Jam't 'yn Shms. Alqahrh. Msr.

4. Khlyl, Mhsn (1982). Alqda' Aledary Allbnany. Drash Mqarnh. Dar Alnhdh.

5. Kn'an, Nwaf (2009). Alqanwn Aledary - Alktab Althany. Dar Althqafh. 'man.

6. Mnswr, Shab Twba (1979). Alqanwn Aledary. Alktab Alawl. Jam't Bghdad.

7. Qbylat, Hmdy (2008). Alqanwn Aledary, Mahyt Alqanwn Aledary, Altnzym Aledary, Alnshat Aledary. Altb'h Alawla.Dar Wa'l.

8. Qbylat, Hmdy (2010). Alqanwn Aledary. Aljz' Althany. Altb'h Alawla. Dar Wa'l Llnshr.

9. Shtnawy, 'ly Khtar (1995). Alqda' Aledary Alardny. Alktab Alawl. Altb'h Alawla. M'sst Wa'l Llnskh Alsry'. 'man.

10. Alslamy, Mhmd (1993). Mbada' Wahkam Alqanwn Aledary. Jam't Bghdad.

11. Altmawy, Slyman (1966). Alnzryat Al'amh Fy Alqrarat Aledaryh. Altb'h Alawla. Dar Alfkr Al'rby. Alqahrh. Msr.

12. Altmawy, Slyman (1984). Alnzryh Al'amh Llqrarat Aledaryh. Dar Alfkr Al'rby. Altb'h Alkhamsh.

13. Alqysy, A'ad 'ly Hmwd (1998). Alwjyz Fy Alqanwn Aledary. Alawla. Dar Wa'l Llnshr. 'man. 